\title{
Steric effects vs electron delocalization: a new look into stability of diastereomers, conformers and constitutional Isomers ${ }^{\dagger}$
}

Received 13th April 2021, Accepted 00th May 2021

DOI: $10.1039 / x 0 x x 00000 x$

\author{
Sopanant Datta (D) and Taweetham Limpanuparb (D) *a
}

A quantum chemical investigation of the stability of compounds with identical formulas was carried out on 23 classes of compounds made of $\mathrm{C}, \mathrm{N}, \mathrm{P}, \mathrm{O}, \mathrm{S}$ atoms as core structures and halogens $\mathrm{H}, \mathrm{F}, \mathrm{Cl}, \mathrm{Br}, \mathrm{I}$ as substituents. All possible structures were generated and investigated by quantum mechanical methods. The prevalence of formula in which its $Z$ configuration, gauche conformation and meta isomer are the most stable forms is calculated and discussed. Quantitative and qualitative models to explain the stability of the 23 classes of halogenated compounds were also proposed.

\section{Introduction}

Steric effects, non-bonded interactions leading to avoidance of spatial congestion of atoms or groups, are often the central theme in the discussion of stability of diastereomers, conformers and constitutional isomers. Reasonings based on steric effects are relatively intuitive and give rise to a generally accepted rule of thumb that $E$ configuration, anti conformer and para isomer in diastereomers, conformational and constitutional isomers, respectively, should be the most stable forms.

Many findings in contrary to steric predictions exist in the literature. Table 1 shows experimental and theoretical investigations of the $Z$ configuration, gauche conformer and meta isomer being the most stable forms in carbon-backbone compounds. The experiments include heat of combustion or hydrogenation and spectroscopic measurement while the theoretical studies are mainly quantum mechanical methods.

Even when steric effect reasoning correctly predicts the result, controversy ensues. For example, a number of organic chemistry textbooks attributed the relative stability of the staggered conformation of ethane to steric factor alone. This has led to controversy discussed at length across the scientific community over eight years. ${ }^{1-8}$

Electron delocalization, on the other hand, are relatively more complicated. The reasoning for energy prediction often involves resonance structures ${ }^{9-15}$ (formerly called mesomeric effect) or hyperconjugation ${ }^{16-20}$ (delocalization) of orbitals. Specific reasonings for each case of exceptions to steric prediction are shown in Table 1 . The preference of $Z$ configuration and gauche conformer are primarily due to

\footnotetext{
a. Science Division, Mahidol University International College, Mahidol University, Salaya, Nakhon Pathom 73170, Thailand.Email: taweetham.lim@mahidol.edu

+ Electronic Supplementary Information (ESI) available. The data presented in this study are openly available in Open Science Framework with a reference number 6ECP4. See DOI: 10.17605/OSF.IO/6ECP4.
}

hyperconjugation in a similar vein to the ethane case, ${ }^{17,}{ }^{18}$ but the reasoning for preference of meta isomer is still lacking.

In addition to carbon-backbone compounds in Table 1, there are many experimental and theoretical studies for other backbones in this study, namely $\mathrm{C}_{3},{ }^{21} \mathrm{C}=\mathrm{N},{ }^{22,}{ }^{23} \mathrm{C}=\mathrm{P},{ }^{24} \mathrm{~N}=\mathrm{N},{ }^{25-31}$ $\mathrm{N}=\mathrm{P},{ }^{32} \mathrm{P}=\mathrm{P},{ }^{33,}{ }^{34} \mathrm{C}-\mathrm{N},{ }^{35} \mathrm{C}-\mathrm{P},{ }^{36,},{ }^{37} \mathrm{C}-\mathrm{O},{ }^{38-40} \mathrm{C}-\mathrm{S},{ }^{41} \mathrm{~N}-\mathrm{N},{ }^{38,42-44} \mathrm{~N}-\mathrm{P},{ }^{38,}$ $43 \mathrm{P}-\mathrm{P},{ }^{38,43,} 45,46 \mathrm{~N}-\mathrm{O},{ }^{38,} 42,47 \mathrm{~N}-\mathrm{S},{ }^{47} \mathrm{P}-\mathrm{O},{ }^{48,}, 49 \mathrm{P}-\mathrm{S},{ }^{50} \mathrm{O}-\mathrm{O},{ }^{38,} 42,51,52$ O-S, ${ }^{53,54}$ and S-S. ${ }^{38,55}$

Inspired by Bent's rule, ${ }^{21,56}$ which states how orbital hybridizations can explain trends of bond lengths and bond angles in a series of compounds correctly while the steric argument fails, in this paper, we want to advance the understanding of energy prediction of chemical structures that are derived from the same molecular formula.

Non-superimposable structures of the same molecular formula can be enantiomers, diastereomers, conformers and constitutional isomers (structural isomers). As energies of enantiomers are identical, they are excluded from our investigation. For the other three types of isomerism, $E$ and $Z$ configurations in $A=A^{\prime}$ compounds and halocyclopropanes represent diastereomerism, gauche and anti conformers in A-A' compounds represent conformational isomerism and ortho, meta and para structure in halobenzenes represent constitutional isomerism.

\section{Materials and methods}

\subsection{Quantum chemical calculations and datasets}

All possible structures made of two atoms $A=A^{\prime}$ and $A-A^{\prime}$ where $A, A^{\prime} \in\{C, N, P, O, S\}$ or $C_{3}$ or $C_{6}$ as the core structure and combinations of halogen $(\mathrm{H}, \mathrm{F}, \mathrm{Cl}, \mathrm{Br}, \mathrm{I})$ as substituents were previously generated by our group. ${ }^{57-59} \mathrm{Up}$ to four levels of theory (HF, B3LYP, MP2 and CCSD) were used in these studies and B3LYP frequency calculations were completed for all structures. As shown in Table 2, we improved upon existing results by performing single-point electronic energy calculation at $\operatorname{CCSD}(T) / 6-311++G(d, p)$ on diastereomer and conformer groups. For the constitutional isomer group, original MP2/6- 
$311++G(d, p)$ energies were used due to prohibitive computational cost of $\operatorname{CCSD}(\mathrm{T})$ in benzene class of compounds. Our choice of methodology was inspired by observations in three dihaloethenes that $\mathrm{HF}$ is not good enough for geometries and MP2 is better than DFT for energy calculation. ${ }^{18} \mathrm{HF}$ and B3LYP results are available in the ESIt for comparison. We used them for diagnostic purpose in some difficult cases of rotamers.

Table 1. Summary of exceptions to steric prediction for carbon-backbone compounds in gas phase

\begin{tabular}{|c|c|}
\hline Case & Exceptions to steric prediction and reasonings \\
\hline 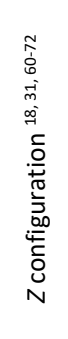 & 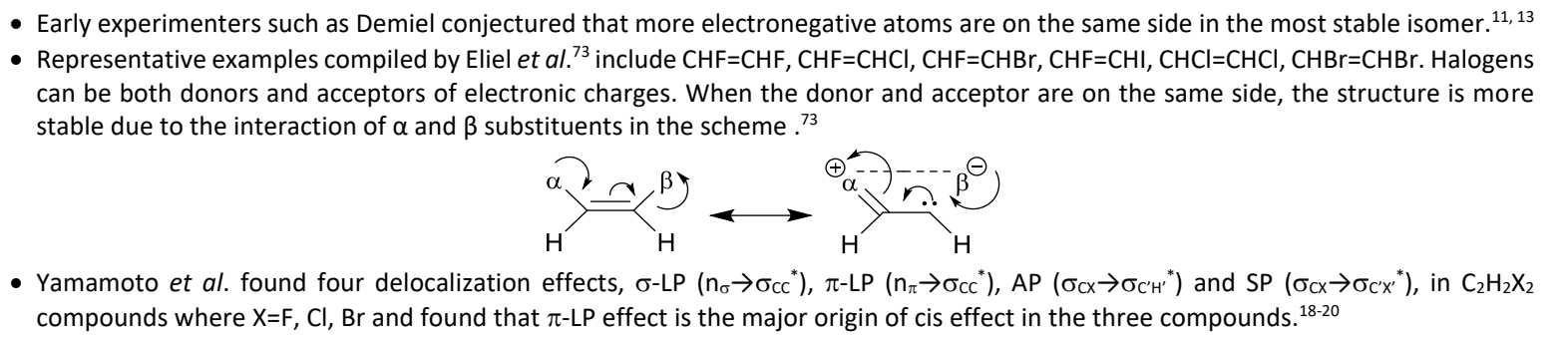 \\
\hline 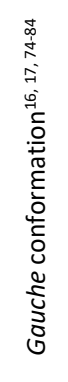 & $\begin{array}{l}\text { - For } \mathrm{CH}_{2} \mathrm{~F}-\mathrm{CH}_{2} \mathrm{~F} \text {, the gauche form is preferred }{ }^{73} \text { due to the hyperconjugative interactions. The dominant one is the antiperiplanar } \sigma_{\mathrm{CH}} \text { to } \\
\sigma_{\mathrm{CF}}{ }^{*} \text { delocalization }{ }^{17} \text { described in the scheme. } \\
\text { - Potential energy surfaces of rotamers have been thoroughly investigated. For } \mathrm{CH}_{2} \mathrm{~F}-\mathrm{CH}_{2} \mathrm{~F} \text {, the twofold }\left(\mathrm{V}_{2}\right) \text { potential actually has an energy } \\
\text { minimum when the } \mathrm{F}-\mathrm{C}-\mathrm{C}-\mathrm{F} \text { torsional angle is } \pm 90^{\circ} .{ }^{79} \text { Rotational barriers can be small such that the shift in equilibrium can be easily } \\
\text { observed when polar solvents promote the interconversion of anti to gauche conformers. } \\
\text { "Bent bond" may offer an explanation for the destabilization of the anti conformer. }{ }^{17,80,81}\end{array}$ \\
\hline
\end{tabular}

- For difluorobenzene, heat of combustion results clearly showed that the meta isomer is the most stable. ${ }^{87}$

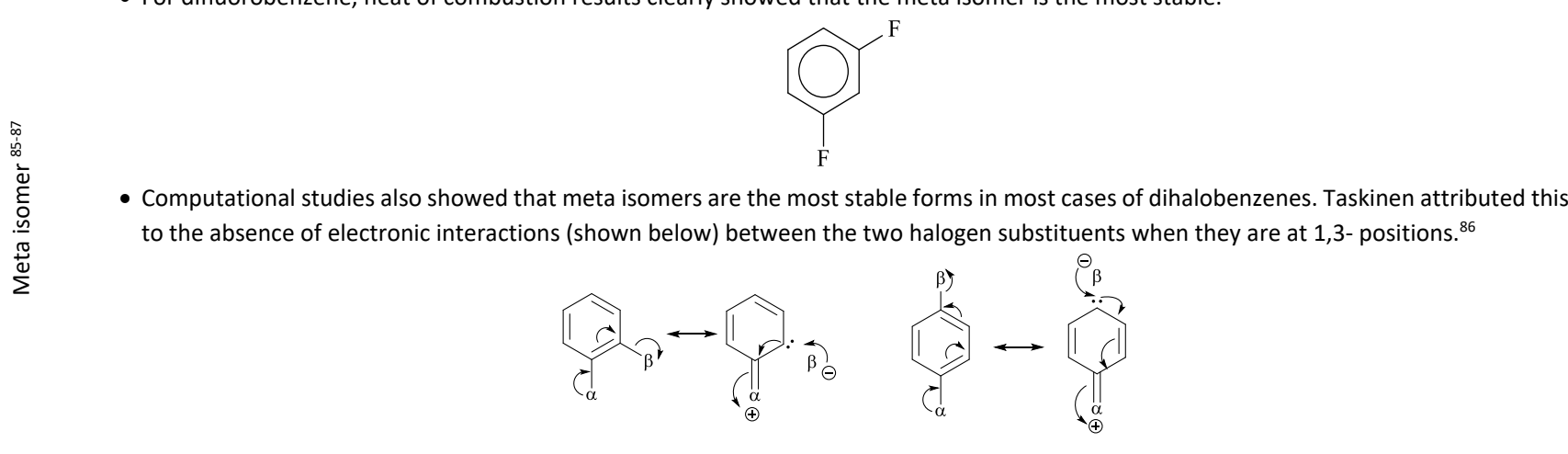

Pople's basis set of $6-311++G(d, p)$ was used due to the availability of iodine atom and its reasonable computational cost. However, Pople's basis sets are well-known to produce imaginary frequency under certain conditions. ${ }^{88}$ Therefore, sample frequency calculations at MP2/6-311++G(d,p) were performed on all classes and only the benzene class was found to have imaginary frequencies. In agreement to the previous study, ${ }^{88}$ we found that imaginary frequencies disappear at MP2/6-311G(d,p) and the electronic energies are very close to $\mathrm{MP} 2 / 6-311++\mathrm{G}(\mathrm{d}, \mathrm{p})$. While mean absolute deviation is 12.4 $\mathrm{kcal} / \mathrm{mol}$ from 1505 structures, $R^{2}$ and slope for the energies from the two basis sets are virtually unity. In other words, energies of all structure are shifted by similar magnitudes in the same direction. As a result, we use the basis $6-311++G(d, p)$ consistently for all classes of compounds in this study.
Optimized geometries of selected $A=A^{\prime}, A-A^{\prime}$ and halobenzene compounds were compared to gas-phase experimental data in previous studies. ${ }^{18,89,90}$ The current level of theory and/or basis set yields acceptable results. Additional confirmation with solid-phase X-ray structures from the Cambridge Structural Database (CSD) ${ }^{91}$ shows good agreement between calculated geometries from the current work and experimental results from the database for dichlorobenzenes. (See the ESIt for the results.)

Revised dataset of all classes of compounds in the previous studies together with additions from this work are available online in Open Science Framework. This new data repository is intended to supersede the three separate datasets. ${ }^{57-59}$ Raw output files from Q-Chem ${ }^{92}$, lists of structures, energies, PubChem CIDs, detailed methodology, source codes, scripts and templates are included. Unless specified differently, default 
settings of $\mathrm{Q}$-Chem were used for the calculations. For some difficult cases of rotamers, different convergence criteria for energies and forces were applied. These attempts can be clearly seen in datasets in the ESI. ${ }^{+}$

Table 2. Class of compounds and the number of structures for the purpose of prevalence rate calculation

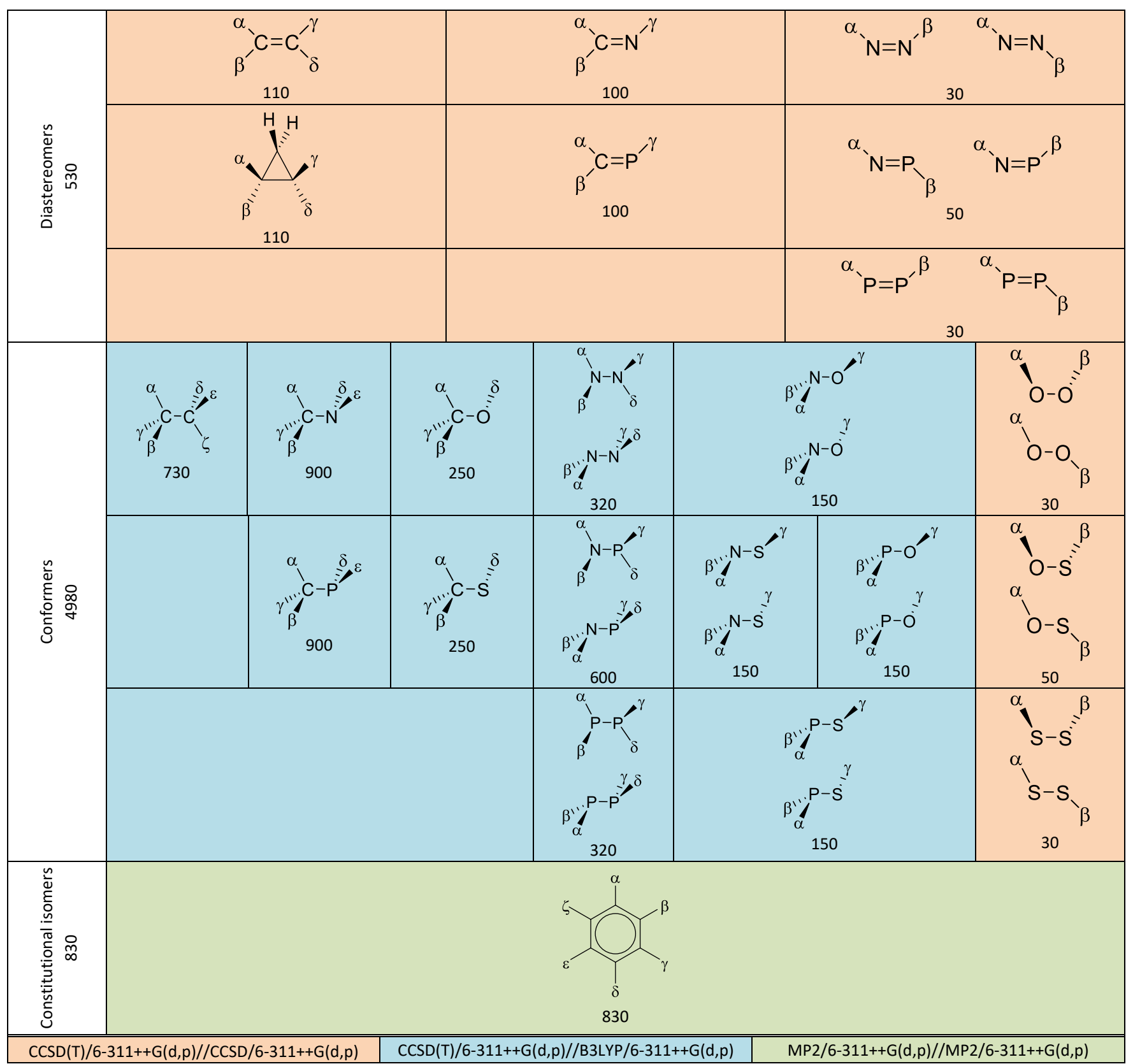

\subsection{Definitions of convention and labels}

We followed the standard definitions as per the Cahn-IngoldPrelog (CIP) sequence rules and the International Union of Pure and Applied Chemistry (IUPAC)'s definitions. The relative bulkiness of all substituents (by covalent or van der Waals radii) in this study also follows the priority rule by chance.

For $E$ and $Z$ configuration of diastereomers, if all four substituents are different, there are six possible isomers on a halo-substituted $\mathrm{C}=\mathrm{C}$. To differentiate them, labels of $E \mathrm{a}, E \mathrm{~b}, E 1$, $E 2, E 3, Z$ a , Zb, Z1, Z2, Z3, G0, G1, G3 ( $G$ stands for geminal.) were used for $\mathrm{C}=\mathrm{C}$ and six other classes of compounds in accordance with the previous study. ${ }^{57}$ Therefore, energy comparison can be made within a diastereomeric pair (same label such as $E 1$ vs $Z 1$ ) and geminal compounds were excluded from the current study.

In a similar manner, for gauche and anti conformers, the torsional angle of the highest-priority substituents per CIP rules from the two ends of the molecule are considered. The angles of $\left(-120^{\circ}, 120^{\circ}\right)$ are treated as gauche and the angles of $\left[-180^{\circ}\right.$, $\left.-120^{\circ}\right)$ or $\left(120^{\circ}, 180^{\circ}\right]$ are counted as anti. Unlike the previous definition of gauche effect, ${ }^{38}$ for simplicity, ambiguous cases (compounds with at least one conformer having ambiguity in labelling) are not considered. For example, all conformers of 
$\mathrm{CBr}_{2} \mathrm{Cl}-\mathrm{CF}_{2} \mathrm{Cl}$ are not considered since the presence of the two $\mathrm{Br}$ atoms as the highest priority atoms on the left leads to an ambiguity in labelling the conformers as gauche or anti. However, compounds with more than one gauche conformer are considered normally in this paper.

For constitutional isomers of halobenzenes, we extended the standard nomenclature ortho, meta, para in disubstituted benzenes to highly substituted benzenes if it can be done by using the two highest priority substituents without ambiguity for all isomers in an empirical formula. For example, $\mathrm{C}_{6} \mathrm{~F}_{4} \mathrm{Cl}_{2}$ isomers can be considered but $\mathrm{C}_{6} \mathrm{Cl}_{4} \mathrm{~F}_{2}$ isomers are not included in our analysis.

As per the definition above, steric effects therefore predict that the $E$ configuration, the anti conformer and the para isomer for compounds in this study are the most stable structures. Herein, deviations from these expectations are called $Z$ configuration effect, gauche conformation effect and meta isomer effect respectively. Preliminary exclusion of irrelevant structures mentioned above reduced the total number of structures for the three groups from 710, 8365 and 1505 in previous studies ${ }^{57-59}$ to 530,4980 and 830 , respectively. Table 2 shows breakdowns of these numbers for each class.

The numbers of structures shown in Table 2 may differ from those in the results and analysis due to the following reasons.

- In the $\mathrm{N}=\mathrm{N}$ class, $\mathrm{NBr}=\mathrm{NI}$ and $\mathrm{NI}=\mathrm{NI}$ disintegrated during the CCSD optimization process and are therefore excluded.

- Some conformers interconverted during the geometry optimization process and are excluded from the analysis.

- Enantiomeric structures exist in many conformer classes. Only one from the pair was chosen for quantum chemical calculation. The excluded structures are still included in the analysis using energetic data from their enantiomers.

\section{Results and discussion}

\subsection{Prevalence rates of steric prediction failure}

$Z$ configuration effect in a pair of diastereomers

\begin{tabular}{|c|c|c|c|c|}
\hline$C=C$ & $\mathrm{C}=\mathrm{N}$ & $\mathrm{N}=\mathrm{N}$ & \multirow{3}{*}{\multicolumn{2}{|c|}{$\begin{array}{l}\text { o/m/p isomer effect in } \\
\text { an empirical formula }\end{array}$}} \\
\hline \multirow[t]{3}{*}{$16 \%$} & $62 \%$ & $92 \%$ & & \\
\hline & $C=P$ & $\mathrm{~N}=\mathrm{P}$ & & \\
\hline & $38 \%$ & $80 \%$ & & $1 \%$ \\
\hline$\triangle$ & & $P=P$ & & $88 \%$ \\
\hline $22 \%$ & & $0 \%$ & & $11 \%$ \\
\hline
\end{tabular}

Gauche conformation effect in a compound

\begin{tabular}{|c|c|c|c|c|c|}
\hline$C-C$ & C-N & $\mathrm{C}-\mathrm{O}$ & $\mathrm{N}-\mathrm{N}$ & $\mathrm{N}-\mathrm{O}$ & $0-0$ \\
\hline \multirow[t]{5}{*}{$15 \%$} & $53 \%$ & $45 \%$ & $90 \%$ & $96 \%$ & $100 \%$ \\
\hline & C-P & C-S & $\mathrm{N}-\mathrm{P}$ & $N-S \quad P-O$ & O-S \\
\hline & $22 \%$ & $19 \%$ & $91 \%$ & $98 \% 100 \%$ & $100 \%$ \\
\hline & & & P-P & P-S & S-S \\
\hline & & & $38 \%$ & $70 \%$ & $100 \%$ \\
\hline
\end{tabular}

Figure 1. Percentages of cases in which steric reasoning fails to predict the most stable structure. For a smaller subset of structures from Table of Contents entry, the number of cases for dihalocompounds of ethene, cyclopropane, ethane and benzene are 5/10 (50\%), 0/10 (0\%), 1/10 (10\%) and 10/10 (100\%), respectively.

The main results are shown in Figure 1 as the percentage of total cases for the three groups, the first made of 7 classes of $E / Z$ diastereomers, the second made of 15 classes of anti/gauche conformers and the third made of one class of ortho/meta/para isomers. These prevalence rates can be simply interpreted as how often the steric reasoning fails to identify the most stable structure in these classes of compounds. For two large classes of carbon compounds ( $C=C, C_{3}$ and $C-C$ ), the rates between $15 \%$ to $22 \%$ are not negligible. There are relatively small classes where the rates are as extreme as $0 \%(\mathrm{P}=\mathrm{P}$ only) and $100 \%$ (O$\mathrm{O}, \mathrm{P}-\mathrm{O}, \mathrm{O}-\mathrm{S}$ and $\mathrm{S}-\mathrm{S})$. The increasing trend toward the upper right side of periodic table can be seen from the Figure. For the purpose of this paper, prevalence rates can be regarded as cases in which electron delocalization effects are in the counteracting direction and are stronger than steric effects.

The uncertainty in computational results can be quantified in several ways. The change in level of theory from MP2 in previous studies ${ }^{57-59}$ to $\operatorname{CCSD}(\mathrm{T})$ in the present study leads to a change in prevalence rate in Figure 1 of at most $7 \%$ (C-N). The prevalence rates at various other levels of theory (HF, B3LYP, MP2) with codes that generate them are available in the ESI. + The basis set change from $6-311++G(d, p)$ to $6-311 G(d, p)$ in MP2 optimization jobs of halobenzene compounds has no effect on the distribution of prevalence rates. Figure 2 shows detailed distributions of energy differences as an extension to Figure 1. Most of the distributions appear to be approximately bellshaped if not uniformly distributed. The difference can be very small (e.g. 0.3 to $0.8 \mathrm{kcal} / \mathrm{mol}$ for $\mathrm{P}=\mathrm{P}$ ) and considerably large (e.g. -11.6 to $2.1 \mathrm{kcal} / \mathrm{mol}$ for $\mathrm{N}-\mathrm{N}$ ).

There are borderline cases in both experimental and computational results as the difference in energy can be extremely small. For the example of $\mathrm{CHBr}=\mathrm{CHBr}$ in Table 1 , the gas-phase experimental value for a configuration conversion from $E$ to $Z$ is $-100 \pm 160 \mathrm{cal} / \mathrm{mol}$ in one source ${ }^{60}$ and revised to $90 \pm 240 \mathrm{cal} / \mathrm{mol}$ in another. ${ }^{66}$ The present $\operatorname{CCSD}(\mathrm{T})$ electronic energy agrees with the latter source that the $E$ configuration is more stable. However, in a similar vein to conformers discussed in Table 1, the $Z$ structure is preferred in the liquid phase. ${ }^{66}$

The main results of prevalence rates here agree with experimental and computational studies previously mentioned in the introduction. The well-known cases in carbon compounds in Table 1 summarized in the infamous book by Eliel, Wilen and Mander ${ }^{73}$ were reproduced in the current work with only one exception mentioned above. Moreover, the extreme cases of $0 \%(\mathrm{P}=\mathrm{P})$ and $92 \%(\mathrm{~N}=\mathrm{N})$ are also in line with previous work by others. ${ }^{28,} 30,33,34$ For the majority of halobenzenes, in contrast to steric prediction, meta isomers are the most stable forms. This is confirmed by previous computational results for dihalobezenes. $^{86}$ Similar observations in polychlorinated compounds also confirm this meta preference e.g. for the first few chlorine substitutions to biphenyls (PCB), dibenzo- $p$-dioxins (PCDD) and dibenzofurans (PCDF), the most stable chlorination occurs at meta positions with respect to the other ring. ${ }^{93}$

\subsection{Quantitative and qualitative models for relative stability}

To gain insights into stability of $Z$ configuration, gauche conformation and meta isomer, previous studies have focused on a small number of representative compounds. The total energy of these chemical structures can be partitioned by 
quantum mechanical methods, for example, exchange repulsion for steric effect and four different types of electron delocalization. ${ }^{18}$ Our approach in this paper is different in two ways. First, all possible permutations in a class of compounds were used in the study. Second, the energies were partitioned by statistical methods. The roles of steric and electron delocalization factors in determining the stability of structures were explored using quantitative and qualitative models as shown in Figure 3.
Simple predictors in which their periodic trends are obvious were selected for our preliminary analysis here. To represent steric bulk, one from three measures of atomic size, covalent radius $\left(R_{\mathrm{C}}\right)$, van der Waals radius $\left(R_{\mathrm{V}}\right)$ and atomic radius $\left(R_{\mathrm{A}}\right)$ was used; the first two exhibit the typical trend of $R(\mathrm{H})<R(\mathrm{~F})<R(\mathrm{Cl})$ $<R(\mathrm{Br})<R(\mathrm{I})$ whereas the last leads to the trend of $R(\mathrm{~F})<R(\mathrm{H})<$ $R(\mathrm{Cl})<R(\mathrm{Br})<R(\mathrm{I})$. To represent electron delocalization, one from two measures, electronegativity (Pauling's scale, EN $(H)<$ $\mathrm{EN}(\mathrm{I})<\mathrm{EN}(\mathrm{Br})<\mathrm{EN}(\mathrm{Cl})<\mathrm{EN}(\mathrm{F}))$ and $\mathrm{p} K_{\mathrm{b}}$ of the conjugate base $\mathrm{X}$ $\left(\mathrm{p} K_{\mathrm{b}}\left(\mathrm{H}^{-}\right)<\mathrm{p} K_{\mathrm{b}}\left(\mathrm{F}^{-}\right)<\mathrm{p} K_{\mathrm{b}}\left(\mathrm{Cl}^{-}\right)<\mathrm{p} K_{\mathrm{b}}\left(\mathrm{Br}^{-}\right)<\mathrm{p} K_{\mathrm{b}}\left(\mathrm{I}^{-}\right)\right)$was used.

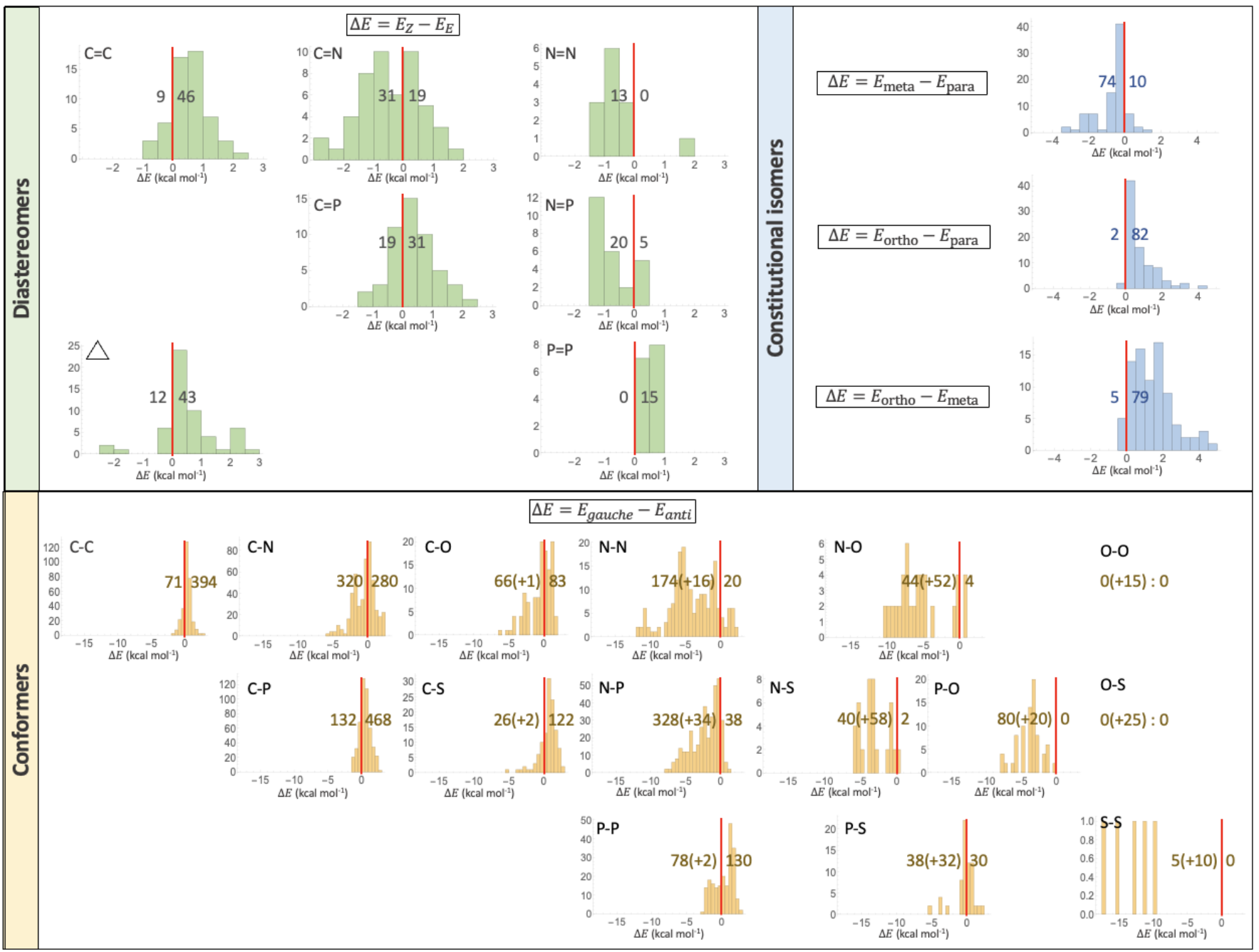

Figure 2. Distribution of electronic energy differences for 23 classes of diastereomers, conformers and constitutional isomers. For conformers and constitutional isomers, whereby more than one form of a kind of structure exists, the form with the lowest energy is considered. The red vertical bars indicate zero. The cases of steric prediction failure are on the left of the bar. Energy differences may not be calculated if some rotamers are not local minima on the potential energy surface. If the only anti conformers are not minima, the compounds must be excluded from the histogram and the number of such compounds are shown as (+xx) on the left of the red vertical bar (gauche side).

\subsubsection{Quantitative model}

According to Table 1, Demiel conjectured that the $Z$ isomers of haloethenes that are more stable than their $E$ counterparts generally have more electronegative substituents on the same side, suggesting how this property gives rise to the $Z$ configuration effect. From this, a multiple linear regression analysis was performed on our data set to study this occurrence along with analogous occurrences in the groups of conformers and constitutional isomers. Linear regression models were generated to predict the $\operatorname{CCSD}(\mathrm{T})$ or MP2 formation energy $\left(E_{\mathrm{f}}\right)$ of all structures (inclusive of those not used for prevalence rate calculation), partitioned into energy from steric effects $\left(E_{r}\right)$ and electron delocalization effects $\left(E_{e}\right) . E_{r}$ and $E_{e}$ are composed of up to three-body terms representing interactions between different substituents, using their steric $\left(r_{i}\right)$ and electronic $\left(e_{i}\right)$ properties. The aim of this analysis is to depict the counteracting effects of steric interaction and electron delocalization by assessing each model's $R^{2}$ value and coefficients. That is, the coefficients should suggest that the 
steric terms favour $E$ interaction over $Z$ interaction in diastereomers, anti interaction over gauche interaction in conformers and para interaction over meta interaction in constitutional isomers and vice versa for the electron delocalization terms. As the energy of all structures in the classes are known, the use of regression here is not to predict the energy of any structure but to use coefficients from regression models to make sense of a large number of available energy data points.

The models for all classes of compounds with all combinations of steric and electron delocalization factors, together with detailed descriptions can be found in the ESI. + This analysis can be conducted on a class of compounds or a larger group of classes. In the latter case, additional term(s) are required to represent the class a compound belongs to (mean $E_{\mathrm{f}}$ within a class or central atom properties). An $R_{\mathrm{v}} \mathrm{vs} \mathrm{p} K_{\mathrm{b}}$ model created for the diastereomers group is shown in Table 3 as an example. In this model, the additional predictor $A$ is the mean
$E_{\mathrm{f}}$ of a class of compounds. The expectation for coefficient trends of $c_{r 2}>c_{r 3}$ and $c_{e 2}<c_{e 3}$ would represent the aforementioned counteracting effects in diastereomers. The resulting coefficients are as expected. As shown in the example of prediction result, $\mathrm{CHF}=\mathrm{CHI}$ is predicted to be more stable in its $Z$ configuration whereas $\mathrm{CHI}=\mathrm{CHI}$ is predicted to be more stable in its $E$ configuration. Cases whereby the final prediction indicates a more stable $E$ configuration can be regarded as those having the more prominent steric effects overpowering electron delocalization effects. The vice versa is applied if $Z$ configuration turns out to be more stable. The $R_{\mathrm{v}}$ (or $R_{\mathrm{C}}$ ) vs $\mathrm{p} K_{\mathrm{b}}$ models resulted in expected coefficient trends for conformers (all classes of compounds in one model) and constitutional isomers as well.

However, regression models using other combinations of steric and electron delocalization factors, especially with EN as the electron delocalization factor, often did not result in expected coefficient trends.

Table 3. Regression model for $\operatorname{CCSD}(\mathrm{T}) / 6-311++\mathrm{G}(\mathrm{d}, \mathrm{p}) / / \mathrm{CCSD} / 6-311++\mathrm{G}(\mathrm{d}, \mathrm{p})$ formation energy $\left(E_{\mathrm{f}}\right)$ in $\mathrm{kcal} / \mathrm{mol}$ of diastereomers (all classes in one model) based on $R_{\mathrm{V}}$ and $\mathrm{p} K_{\mathrm{b}}$

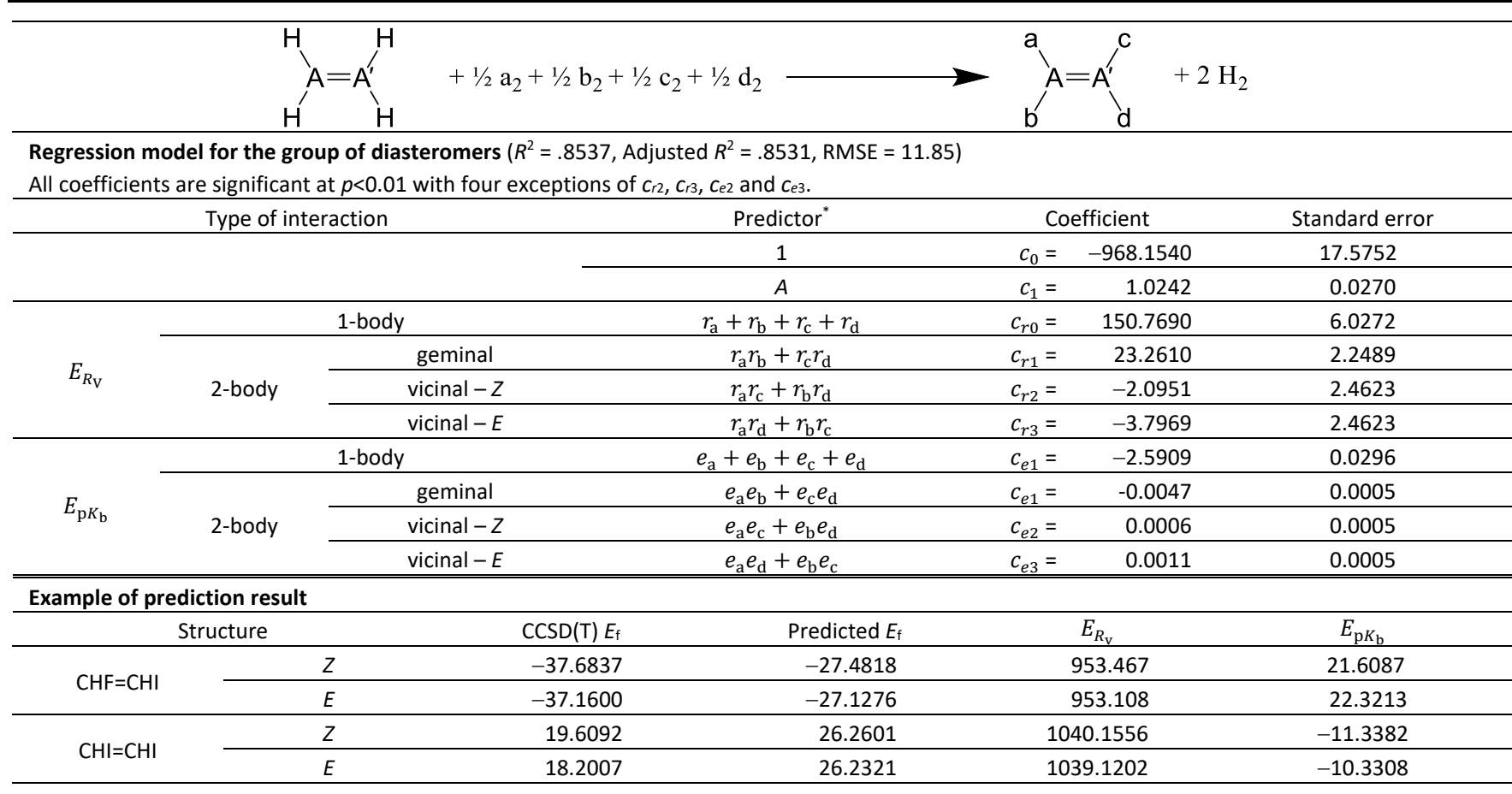

${ }^{*} r_{i}$ and $e_{i}$ are values of the steric factor $r\left(R_{\mathrm{V}}\right.$ in $\AA$ ) and the electron delocalization factor e ( $\mathrm{p} K_{\mathrm{b}}$ - unitless), respectively, of substituent $i(i \in\{\mathrm{a}, \mathrm{b}, \mathrm{c}, \mathrm{d}\})$. The unit of coefficients can be inferred from this information and the nature of one and two-body terms.

\subsubsection{Qualitative model}

Our qualitative model concerns structure classification based on steric and electron delocalization factors and uses the contingency table approach to assess the influence of different factors on the stability of structures. Factors were applied in the same way atomic numbers are used in the CIP rule to classify structures as $E / Z$, anti/gauche and ortho/meta/para. (See Definition of convention and labels section.) To construct a contingency table, structures within a class of compounds were classified by one steric factor ( $R_{\mathrm{C}}$ or $R_{\mathrm{A}} ; R_{\mathrm{V}}$ is not included in our consideration as it provides the same ranking as $R_{\mathrm{C}}$ ) and one electron delocalization factor $\left(E N\right.$ or $\mathrm{p} K_{\mathrm{b}}$ ). This was performed to reveal kinds of structures that are supposed to be favoured by both steric and electron delocalization factors and those favoured by one but not by the other. Then, under each classification, the percentage of structures being the most stable in relation to their counterparts were determined. The expectation from this calculation is that for classifications that are not favoured by both the steric and the electron delocalization factor, a final $0 \%$ should be achieved. For classifications that are favoured by both factors, a $100 \%$ should be achieved.

For each class of compounds, four contingency tables from four different combinations of steric and electron delocalization factors were constructed and can be found in the ESI. + The $R_{C}$ vs $\mathrm{p} K_{\mathrm{b}}$ model provides results that can be considered the same 
as those in Figure 1, as the two factors give identical substituent rankings. The prevalence rates are obtained from the counts of structures classified as $Z$ configuration, gauche conformer or meta isomer by both factors.

An example of a contingency table is shown in Figure 3 for the class of $\mathrm{C}=\mathrm{C}$ compounds under the $R_{\mathrm{c}} \mathrm{vS} \mathrm{EN}$ model. For this model, the assumption is that the steric factor favours the $E$ configuration $\left(E_{\mathrm{RC}}\right)$ whereas the electron delocalization factor favours the $Z$ configuration $\left(Z_{\mathrm{EN}}\right) \cdot{ }^{11,13}$ Therefore, a final $100 \%$ is expected from an $E_{\mathrm{RC}}$ and $Z_{\mathrm{EN}}$ structure and a $0 \%$ from its isomeric counterpart $\left(\mathrm{Z}_{\mathrm{RC}}\right.$ and $\left.\mathrm{E}_{\mathrm{EN}}\right)$. There are $24 \mathrm{C}=\mathrm{C}$ structures of this classification, of which 20 structures are the most stable in their diastereomeric pairs. This shows that $20 / 24=83 \%$ of $E_{\mathrm{RC}}$ and $Z_{\mathrm{EN}}$ structures are the most stable compared to their diastereomers. Neither a $100 \%$ nor a $0 \%$ were attained from the other two classifications $\left(Z_{\mathrm{RC}}\right.$ and $Z_{\mathrm{EN}}$, and $E_{\mathrm{RC}}$ and $\left.E_{\mathrm{EN}}\right)$ in this class of compounds. Expected results (0\% and 100\%) were achieved for $\mathrm{C}=\mathrm{N}, \mathrm{C}=\mathrm{P}$ and cyclopropane as described in the ESI. + However, this is relatively small compared to the number of classes of compounds in which expected results were not achieved. Thus, this qualitative model was not able to illustrate conclusive results across all classes of compounds of diastereomers, conformers and constitutional isomers.

\subsection{Improvement on the two models}

Deviations from expected results in both quantitative and qualitative models above could be explained or addressed in three ways.

There could be a third factor affecting the results. For example, the deviation from idealized geometry was considered by performing both quantitative and qualitative analyses on the unoptimized structures, using standard bond lengths and bond/torsional angles. Improved trends were observed as described in the ESI. +

Steric and electron delocalization predictors are highly correlated as per the periodic trend. A more appropriate electronic predictor may help improve the model. Steric factors may, in fact, be negligible when compared to electron delocalization factors for the studied classes of compounds after appropriate treatment of electron delocalization terms are employed.

In cases of qualitative models for conformers and constitutional isomers, only considering the pair of highest priority substituents has an inherent flaw and may not reflect the summative effect of all substituents.

\section{Conclusions, implications and future work}

Most previous studies focused on a few model compounds and orbital-based energy partition schemes. To the best of our knowledge, our work is the first attempt to use combinatorics to enumerate ${ }^{94}$ all possible compounds and to employ statistical methods for energy partition schemes. The prevalence rates strongly support that the phenomenon ${ }^{8}$ of $Z$ configuration effect, gauche conformation effect and meta isomer effect are real and not negligible.
The implications for teaching are manifold. Many general, organic and biochemistry (GOB) textbooks ${ }^{95-97}$ mention the relative stability of $E / Z$ (cis-trans or geometric) isomers but neglect to mention these phenomena probably for simplicity or because the phenomena were thought to be rare. There are two possible changes. First, one must be apprehensive when the steric reasoning is used to make stability predictions of compounds based on the size of halogen substituents. Second, for reasoning of these phenomena, there should be a more balanced view or a shift from teaching of VSEPR (steric-driven reasoning) to Bent's rule ${ }^{98}$ and hyperconjugation (electron delocalization-driven reasoning). The call to move away from VSEPR $^{99,} 100$ has been discussed elsewhere and this work only provides an additional piece of supporting evidence. It is important to note that even in the case that the steric prediction is right, the hyperconjugation energy can still be dominant as in the controversial case of ethane rotational barrier. ${ }^{1-8}$

The data presented should lead to a renewed interest in finding a new approach to describe stability of chemical compounds. The dataset is open for further analysis and utilization in many ways. For example, the models can be applied in molecular mechanics force field construction. Further analysis of bond length and bond angles for different structural classifications may reveal important insights into the three phenomena. Also, we are aware that constitutional isomers exist within the group of diastereomers (only $\mathrm{C}=\mathrm{C}, \mathrm{C}=\mathrm{N}$, and $\mathrm{C}=\mathrm{P}$ ). There is currently no specific naming convention for the relationship. Preliminary analysis shows that the failure rate of steric prediction from 1,2 interchange of substituents is $24 / 55$, $32 / 50$ and $25 / 50$, respectively for the three classes. For example, the geminal structure of $\mathrm{C}_{2} \mathrm{~F}_{2} \mathrm{I}_{2}$ is more stable than its $E$ structure. (See the ESIt for the complete list.) Similarly, constitutional isomers do exist within the group of conformers too but an exchange of two substituents will have the constitutional isomer effect intertwined with conformational isomer effect.

It is possible to further improve upon the levels of theory and basis used in this study. Specifically, Pople's basis sets are known for issues with post-HF calculations. A well-balanced approach should be developed for this particular area of study. Application of machine learning techniques may also help make a better sense of the data set and reduce the number of structures required to undergo expensive quantum mechanical calculations.

\section{Author Contributions}

S.D. and T.L. contributed equally. All authors have given approval to the final version of the manuscript.

\section{Conflicts of interest}

There are no conflicts to declare.

\section{Acknowledgements}


This research was supported by mid-career researcher development grant (NRCT5-RSA63015-22) jointly funded by the National Research Council of Thailand (NRCT) and Mahidol University. The funders had no role in study design, data collection and analysis, decision to publish, or preparation of the manuscript. We are grateful to Kridtin Chinsukserm, Peter Gill, Junming Ho, Wanutcha Lorpaiboon and Pierre Priest for analysis, ideas and suggestions in the early phase of this project. We thank the organizing committee of the $24^{\text {th }}$ international annual symposium on computational science and engineering (ANSCSE24) for invitation to give a talk on 29 April 2021.

\section{Notes and references}

1. V. Pophristic and L. Goodman, Nature, 2001, 411, 565-568.

2. F. Weinhold, Nature, 2001, 411, 539-541.

3. P. R. Schreiner, Angew. Chem. Int. Ed., 2002, 41, 3579-3582.

4. F. M. Bickelhaupt and E. J. Baerends, Angew. Chem. Int. Ed., 2003, 42, 4183-4188.

5. F. Weinhold, Angew. Chem. Int. Ed., 2003, 42, 4188-4194.

6. Y. Mo, W. Wu, L. Song, M. Lin, Q. Zhang and J. Gao, Angew. Chem. Int. Ed., 2004, 43, 1986-1990.

7. Y. Mo and J. Gao, Acc. Chem. Res., 2007, 40, 113-119.

8. S. Liu, N. Govind and L. G. Pedersen, J. Chem. Phys., 2008, 129, 094104.

9. L. Pauling, L. O. Brockway and J. Y. Beach, J. Am. Chem. Soc., 1935, 57, 2705-2709.

10. K. S. Pitzer and J. L. Hollenberg, J. Am. Chem. Soc., 1954, 76, 1493-1496.

11. A. Demiel, J. Org. Chem., 1962, 27, 3500-3504.

12. G. B. Savitsky and K. Namikawa, J. Phys. Chem., 1963, 67, 2754-2756.

13. A. Demiel, J. Org. Chem., 1965, 30, 2121-2126.

14. J. Reuben and A. Demiel, J. Chem. Phys., 1966, 44, 2216-2217.

15. J. T. Waldron and W. H. Snyder, J. Am. Chem. Soc., 1973, 95, 5491-5495.

16. N. C. Craig, A. Chen, K. H. Suh, S. Klee, G. C. Mellau, B. P. Winnewisser and M. Winnewisser, J. Am. Chem. Soc., 1997, 119, 4789-4790.

17. L. Goodman, H. Gu and V. Pophristic, J. Phys. Chem. A, 2005, 109, 1223-1229.

18. T. Yamamoto, D. Kaneno and S. Tomoda, Bull. Chem. Soc. Jpn., 2008, 81, 1415-1422.

19. I. V. Alabugin, K. M. Gilmore and P. W. Peterson, Wiley Interdiscip. Rev. Comput. Mol. Sci., 2011, 1, 109-141.

20. I. V. Alabugin, G. dos Passos Gomes and M. A. Abdo, Wiley Interdiscip. Rev. Comput. Mol. Sci., 2019, 9, e1389.

21. I. V. Alabugin, S. Bresch and M. Manoharan, J. Phys. Chem. A, 2014, 118, 3663-3677.

22. J. M. Howell, J. Am. Chem. Soc., 1976, 98, 886-887.

23. H. G. Li, C. K. Kim, B. S. Lee, C. K. Kim, S. K. Rhee and I. Lee, J. Am. Chem. Soc., 2001, 123, 2326-2333.

24. M. T. Nguyen, A. Van Keer and L. G. Vanquickenborne, J. Organomet. Chem., 1997, 529, 3-14.

25. G. T. Armstrong and S. Marantz, J. Chem. Phys., 1963, 38, 169172.

26. N. Wiberg, G. Fischer and H. Bachhuber, Angew. Chem. Int. Ed., 1977, 16, 780-781.

27. K. Nordhoff and E. Anders, J. Org. Chem., 1999, 64, 74857491.
28. G. S. Tschumper, M. C. Heaven and K. Morokuma, Chem. Phys. Lett., 2003, 370, 418-424.

29. P. R. P. Barreto, A. F. A. Vilela and R. Gargano, Int. J. Quantum Chem., 2005, 103, 659-684.

30. T. Yamamoto, D. Kaneno and S. Tomoda, J. Org. Chem., 2008, 73, 5429-5435.

31. D. Banerjee, A. Ghosh, S. Chattopadhyay, P. Ghosh and R. K. Chaudhuri, Mol. Phys., 2014, 112, 3206-3224.

32. X. Zeng, H. Beckers and H. Willner, Angew. Chem. Int. Ed., 2009, 48, 4828-4831.

33. T. Lu, A. C. Simmonett, F. A. Evangelista, Y. Yamaguchi and H. F. Schaefer, J. Phys. Chem. A, 2009, 113, 13227-13236.

34. S. Vogt-Geisse and H. F. Schaefer, J. Chem. Theory Comput., 2012, 8, 1663-1670.

35. J. J. Irwin, T. K. Ha and J. D. Dunitz, Helv. Chim. Acta, 1990, 73, 1805-1817.

36. P. Coppens, B. J. van der Veken and J. R. Durig, J. Mol. Struct., 1986, 142, 367-370.

37. E. C. Wang, Y. S. Li and R. A. Beaudet, J. Mol. Struct., 1990, 223, 15-32.

38. S. Wolfe, Acc. Chem. Res., 1972, 5, 102-111.

39. S. Wolfe, L. M. Tel, W. J. Haines, M. A. Robb and I. G. Csizmadia, J. Am. Chem. Soc., 1973, 95, 4863-4870.

40. K. Omoto, K. Marusaki, H. Hirao, M. Imade and H. Fujimoto, J. Phys. Chem. A, 2000, 104, 6499-6504.

41. C. F. Su and C. R. Quade, J. Chem. Phys., 1983, 79, 5828-5834.

42. F. A. Van-Catledge, J. Am. Chem. Soc., 1974, 96, 5693-5701.

43. A. H. Cowley, D. J. Mitchell, M.-H. Whangbo and S. Wolfe, J. Am. Chem. Soc., 1979, 101, 5224-5231.

44. H. B. Schlegel and A. Skancke, J. Am. Chem. Soc., 1993, 115, 7465-7471.

45. J. Odom, C. Wurrey, L. Carreira and J. Durig, Inorg. Chem., $1975,14,2849-2853$.

46. K. D. Sen, K. Ohta and K. Morokuma, J. Mol. Struct. THEOCHEM, 1984, 109, 287-292.

47. M. D. Burtzoff, L. Peter, P. A. Lepse and D. Y. Zhang, J. Mol. Struct. THEOCHEM, 2002, 619, 229-239.

48. W. B. Person, J. S. Kwiatkowski and R. J. Bartlett, J. Mol. Struct., 1987, 157, 237-254.

49. R. Withnall and L. Andrews, J. Phys. Chem., 1987, 91, 784-797.

50. M. Korn, H. Oberhammer and R. Minkwitz, J. Mol. Struct., 1993, 300, 61-72.

51. A. Veillard, Chem. Phys. Lett., 1969, 4, 51-52.

52. D. C. Ghosh, Int. J. Mol. Sci., 2006, 7.

53. G. I. Cárdenas-Jirón, J. R. Letelier and A. Toro-Labbé, J. Phys. Chem. A, 1998, 102, 7864-7871.

54. O. Baum, $\mathrm{HSOH}$ - An elusive species with many different traits, Cuvillier Verlag, Göttingen, Germany, 2008.

55. B. P. Prascher and A. K. Wilson, J. Mol. Struct. THEOCHEM, 2007, 814, 1-10.

56. H. A. Bent, Chem. Rev., 1961, 61, 275-311.

57. K. Chinsukserm, W. Lorpaiboon, P. Teeraniramitr and T. Limpanuparb, Data Brief, 2019, 27, 104738.

58. T. Limpanuparb, S. Datta, K. Chinsukserm and P. Teeraniramitr, Data Brief, 2020, 30, 105442.

59. S. Datta and T. Limpanuparb, Data Brief, 2020, 30, 105386.

60. J. M. Dowling, P. G. Puranik, A. G. Meister and S. I. Miller, J. Chem. Phys., 1957, 26, 233-240.

61. H. G. Viehe, Chem. Ber., 1960, 93, 1697-1709.

62. N. C. Craig and E. A. Entemann, J. Am. Chem. Soc., 1961, 83, 3047-3050. 
63. H. G. Viehe and E. Franchimont, Chem. Ber., 1963, 96, 31533158.

64. N. Craig, Y. S. Lo, L. Piper and J. C. Wheeler, J. Phys. Chem., 1970, 74, 1712-1727.

65. N. C. Craig, D. A. Evans, L. G. Piper and V. L. Wheeler, J. Phys. Chem., 1970, 74, 4520-4527.

66. N. C. Craig, L. G. Piper and V. L. Wheeler, J. Phys. Chem., 1971, 75, 1453-1460.

67. D. Dixon, T. Fukunaga and B. E. Smart, J. Am. Chem. Soc., 1986, 108, 1585-1588.

68. J. B. P. da Silva, J. Braz. Chem. Soc., 2000, 11, 219-223.

69. R. Kanakaraju, K. Senthilkumar and P. Kolandaivel, J. Mol. Struct. THEOCHEM, 2002, 589-590, 95-102.

70. N. A. Pradie and H. V. Linnert, J. Phys. Chem. A, 2007, 111, 4836-4848.

71. D. Feller, K. A. Peterson and D. A. Dixon, J. Phys. Chem. A, 2011, 115, 1440-1451.

72. S. Jenkins, S. R. Kirk, C. Rong and D. Yin, Mol. Phys., 2013, 111, 793-805.

73. E. L. Eliel, S. H. Wilen and L. N. Mander, Stereochemistry of Organic Compounds, Wiley, New York, USA, 1994.

74. P. R. Rablen, R. W. Hoffmann, D. A. Hrovat and W. T. Borden, J. Chem. Soc., Perkin Trans. 2, 1999, 1719-1726.

75. F. R. Souza, M. P. Freitas and R. Rittner, J. Mol. Struct. THEOCHEM, 2008, 863, 137-140.

76. D. Y. Buissonneaud, T. van Mourik and D. O'Hagan, Tetrahedron, 2010, 66, 2196-2202.

77. J. C. R. Thacker and P. L. A. Popelier, J. Phys. Chem. A, 2018, 122, 1439-1450.

78. F. A. Martins and M. P. Freitas, Eur. J. Org. Chem., 2019, 2019, 6401-6406.

79. L. Radom, W. A. Lathan, W. J. Hehre and J. A. Pople, J. Am. Chem. Soc., 1973, 95, 693-698.

80. R. C. Bingham, J. Am. Chem. Soc., 1976, 98, 535-540.

81. K. B. Wiberg, M. A. Murcko, K. E. Laidig and P. J. MacDougall, J. Phys. Chem., 1990, 94, 6956-6959.

82. C. Thiehoff, Y. P. Rey and R. Gilmour, Isr. J. Chem., 2017, 57, 92-100.

83. D. O'Hagan, Chem. Soc. Rev., 2008, 37, 308-319.

84. D. R. Silva, L. de Azevedo Santos, T. A. Hamlin, C. Fonseca Guerra, M. P. Freitas and F. M. Bickelhaupt, ChemPhysChem, 2021, 22, 641-648.

85. J. Cioslowski, G. Liu and D. Moncrieff, J. Phys. Chem. A, 1997, 101, 957-960.

86. E. Taskinen, Struct. Chem., 2000, 11, 293-301.

87. W. D. Good, J. L. Lacina, D. W. Scott and J. P. McCullough, J. Phys. Chem., 1962, 66, 1529-1532.

88. D. Moran, A. C. Simmonett, F. E. Leach, W. D. Allen, P. v. R. Schleyer and H. F. Schaefer, J. Am. Chem. Soc., 2006, 128, 9342-9343.

89. M. Baranac-Stojanović, RSC Adv., 2014, 4, 43834-43838.

90. E. Cané, A. Miani and A. Trombetti, Chem. Phys. Lett., 2001, 340, 356-361.

91. C. R. Groom, I. J. Bruno, M. P. Lightfoot and S. C. Ward, Acta Crystallogr. B., 2016, 72, 171-179.

92. Y. Shao, Z. Gan, E. Epifanovsky, A. T. Gilbert, M. Wormit, J. Kussmann, A. W. Lange, A. Behn, J. Deng and X. Feng, Mol. Phys., 2015, 113, 184-215.

93. S. Datta and T. Limpanuparb, Molecules, 2020, 25, 5697.

94. W. Lorpaiboon and T. Limpanuparb, ChemRxiv, 2021, 10.26434/chemrxiv.14571546.
95. R. H. Petrucci, F. G. Herring, J. D. Madura and C. Bissonnette, General chemistry: principles and modern applications, Pearson, New Jersey, USA, 2017.

96. T. W. G. Solomons, C. B. Fryhle and S. A. Snyder, Organic Chemistry, John Wiley \& Sons, Inc., New Jersey, USA, 2016.

97. P. Vollhardt and N. Schore, Organic Chemistry: Structure and Function, W. H. Freeman and Company, New York, USA, 2018.

98. S. Phankingthongkum and T. Limpanuparb, BMC Res. Notes, 2021, 14, 66.

99. I. V. Alabugin, S. Bresch and G. dos Passos Gomes, J. Phys. Org. Chem., 2015, 28, 147-162.

100. F. Weinhold and C. R. Landis, Discovering Chemistry With Natural Bond Orbitals, Wiley, Hoboken, NJ, 2012. 